\title{
Evaluation of the benefits of the introduction of electricity powered vehicles in an island
}

\author{
Patrícia C. Baptista $^{\mathrm{a}, *}$, Carla M. Silva ${ }^{\mathrm{a}}$, J.A. Peças Lopes ${ }^{\mathrm{b}}$, Filipe J. Soares ${ }^{\mathrm{b}}$, Pedro R. Almeida ${ }^{\mathrm{b}}$ \\ a IDMEC, Instituto Superior Técnico, Universidade de Lisboa, Av. Rovisco Pais, 1, 1049-001 Lisboa, Portugal \\ ${ }^{\mathrm{b}}$ Instituto de Engenharia de Sistemas e Computadores do Porto (INESC Porto), Portugal Campus da FEUP, Rua Dr. Roberto Frias, 378, 4200-465 Porto, Portugal
}

\section{A R T I C L E I N F O}

\section{Article history:}

Received 24 January 2013

Accepted 26 July 2013

\section{Keywords:}

Islands' mobility

Electricity powered vehicles

Energy consumption

$\mathrm{CO}_{2}$ emissions

\begin{abstract}
A B S T R A C T
This paper evaluates the benefits of introducing electricity powered vehicles (EV) in one island of the Azores archipelago in Portugal, the island of Flores. A Life Cycle Analysis (LCA) for the road transportation sector including EV was performed and the EV impacts in the electricity grid were evaluated. Two scenarios considering the introduction of EV were considered (Scenarios 2 and 3 with a shift in the car stock in 2050 of $30 \%$ and $70 \%$ to EV) and compared to the baseline scenario (Scenario 1 with no EV penetration). The results show that, if no alternative solutions are adopted, the road transportation sector LCA energy consumption will increase $58 \%$ in 2050 , compared to 2009. In the most attractive scenario studied regarding EV integration in Flores, the LCA energy consumption in 2050 decreases by $34 \%$ and $\mathrm{CO}_{2}$ emissions by $39 \%$, when comparing with Scenario 1 . Moreover, the island's electricity network is ready for EV arrival, at least until 2020. Thereafter, a smart charging scheme should be implemented to manage the vehicles' energy demand according to the network technical limitations and the presence of Renewable Energy Sources (RES) should be reinforced, to decrease the island's dependency on fossil fuels and, consequently, $\mathrm{CO}_{2}$ emissions.
\end{abstract}

(c) 2013 Elsevier Ltd. All rights reserved.

\section{Introduction}

In the last two decades, the Portuguese global energy consumption has risen considerably (around 57\% from 1990 to 2008). The transportation sector accounts for approximately $40 \%$ of the global energy consumption. From this percentage, road transportation sector accounted in 2008 for 80\% [1]. Additionally, Portugal imports most of its transportation final energy consumption in the form of oil based fuels [2]. In terms of greenhouse gas (GHG) emissions, in the 1990-2007 period, the road transportation sector emissions have risen by $92 \%$ [3].

In this context, the urge for energy security of supply, air quality improvement in urban areas and $\mathrm{CO}_{2}$ emissions reduction are pres-

Abbreviations: $\mathrm{CO}_{2}$, carbon dioxide; $\mathrm{CTG}$, cradle-to-grave; DSO, Distribution System Operator; EV, electric vehicles; FC, fuel consumption; GHG, green-house gases; HDV, heavy duty vehicles; HEV, hybrid electric vehicles; ICE, internal combustion engine; INE, Instituto Nacional de Estatística; LCA, life-cycle assessment; LDV, light duty vehicles; LV, low voltage; MV, medium voltage; PATTS Projections for Alternative Transportation Technologies Software; PHEV, plug-in hybrid electric vehicles; RED, Renewable Energy Directive; RES, Renewable Energy Sources; SOC, State-of-Charge; TTW, tank-to-wheel; VKT, vehicle kilometers traveled; WTT, well-to-tank.

* Corresponding author. Address: IDMEC/IST - Instituto Superior Técnico, Dept. of Mechanical Engineering, Av. Rovisco Pais, Pav. Mecânica I, $2^{\circ}$ Andar, 1049-001 Lisbon, Portugal. Tel.: +351 218419555; fax: +351 218417640.

E-mail address: patricia.baptista@ist.utl.pt (P.C. Baptista). suring decision makers and vehicle manufacturers to act on the road transportation sector, by introducing more efficient vehicles in the market and spanning the energy sources available. In this sense, it is expected in the near future that the transportation sector will face considerable changes. The market share of hybrid electric vehicles (HEV) will probably rise and, in the medium-long term future, the market share of alternative technologies such as PHEV, EV or fuel cell vehicles will eventually start increasing.

The European Commission is working on proposals regarding electric vehicles which are described as a "very important" part of its green strategy and the European Parliament has launched a resolution supporting the development and innovation regarding this issue [4]. The Portuguese government is also committed to enforce the introduction of electric vehicles in Portugal and launched the Electric Mobility Plan/“Plano de Mobilidade Eléctrica”, defending that "electric vehicles will be the next logical step from hybrids due to their high potential for $\mathrm{CO}_{2}$ reduction" $[5,6]$. The expected evolution for EV and PHEV vehicles in Portugal, whose actual light-duty fleet comprises roughly 6 million internal combustion vehicles (ca. 50\% diesel, 50\% gasoline), ranges from 8000 existing vehicles in 2012 to $150-200$ thousand in 2020 , representing $10 \%$ of vehicle sales in 2020. However, in terms of actual circulating fleet percentage, these $10 \%$ are expected in the following $10-$ 15 years ahead [7]. The main crucial assumptions for this scenario are: further increasing oil prices; taxation and vehicle incentives 
legislation in Europe continues as announced; availability of high variety of EV and HEV; availability of charging infrastructure; and improvement in battery technology/costs as expected (up to $65 \%$ reductions in battery costs in 2020) [6].

The announced incentives of the Portuguese Government to introduce the use of electricity driven vehicles include the existence of 1300 by 2011, no circulation taxes for EV and income taxes reductions in the acquisition of an electric car [8]. The first 5000 private adopters of EV will also receive a subsidy of $5000 €$ that could be added by an extra $1500 €$ if an old car is scrapped.

Additionally, Portugal has made relevant steps towards the introduction of biofuels in the road transportation sector. Nowadays, up to $7 \%$ introduction of first generation biodiesel is being achieved in regular diesel [9]. In the Portuguese Strategic Energy Technology Plan (SET Plan) [5] future scenarios on biofuels assume that by 2050 biofuels are expected to represent approximately $20 \%$ of total road transport fuel (probably the biggest share of this portion will belong to second generation biofuels). This is in accordance with the recent European Renewable Energy Directive (RED) [10] in transportation which says that by 2020 each member state must have $10 \%$ transportation energy coming from renewable sources.

Few studies address the issue of how long and how significantly the impact of new technologies will influence the energy saving, energy displacement, avoided $\mathrm{CO}_{2}$ emissions and impacts on the electricity grid [11-13]. Preliminary work was performed in order to assess the impacts of integrating different levels of pure electric vehicles and plug-in hybrid vehicles in the grid and in pollutants emissions in a typical electricity distribution network for a residential area in Portugal [14].

This article addresses the specific case of one Portuguese island in the Azores archipelago, the island of Flores, where the energy consumption has risen around 10\% from 2001 to 2007, with the transportation sector accounting for an average of $47 \%$ [15]. An assessment of the benefits of introducing electricity powered vehicles is performed, both for the road transportation sector, in terms of its LCA, and for the impacts in the electricity grid.

\subsection{Flores island characterization}

The island of Flores is the seventh smaller island of the Azores archipelago with just $141 \mathrm{~km}^{2}$. In terms of population it is the second smallest island of Azores with just around 4000 inhabitants [15], as can be seen in Table 1, which corresponds to 29 inhabitants per $\mathrm{km}^{2}$.

Regarding Flores' road transportation fleet, due to the islands' small dimensions, it has a relatively small fleet with just around 2000 light-duty vehicles (LDV) and less than 60 heavy-duty vehicles (HDV) [16]. This corresponds to motorization values for LDV and HDV of 498 and 14 vehicles per 1000 inhabitants respectively. According to the usual evolution of motorization curves [17], it is expected that the LDV and HDV fleets stabilize at around 520 vehicles and 15 vehicles per 1000 inhabitants respectively, compared to the values of 616 and 15 vehicles per 1000 inhabitants for mainland Portugal.

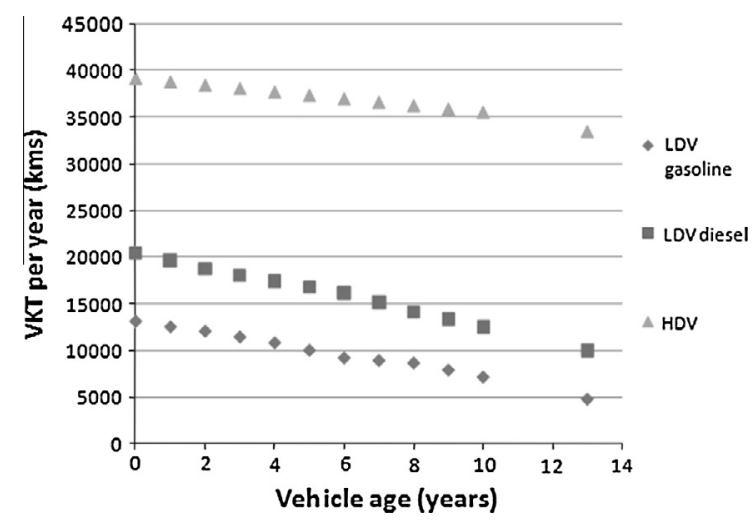

Fig. 1. Vehicle kilometers traveled per year along the vehicle's life.

Table 2

Gasoline and diesel fuel sales for the island of Flores [9].

\begin{tabular}{lll}
\hline \multirow{2}{*}{ Year } & Fuel sales (TJ) & \\
\cline { 2 - 3 } & Gasoline & Diesel \\
\hline 2001 & 20.4 & 59.1 \\
2002 & 18.2 & 42.0 \\
2003 & 17.7 & 54.2 \\
2004 & 17.8 & 66.9 \\
2005 & 22.1 & 68.3 \\
2006 & 20.8 & 63.2 \\
2007 & 19.5 & 62.5 \\
\hline
\end{tabular}

In terms of mobility patterns, the average Azores vehicle kilometers traveled (VKT) along the vehicle's lifetime were used as a reference [18] (see Fig. 1). The high level of VKT may be due to the extensive use of HDV for goods distribution.

As no specific VKT data is available for this island, the mobility data gathered was calibrated so that the final energy consumption by the LDV and HDV fleets matched the historic fuel sales in the island [9] (see Table 2).

For the same reason mentioned above, the home arrival distribution of the vehicles and the fleet movement in this island were assumed to be similar to the light vehicle fleet movement in Portugal. A statistical study [19] was made by INE to evaluate the mobility patterns in several regions in Portugal, namely the hour at which the vehicles arrive home from their last daily journey (Fig. 2).

Concerning the grid architecture and generation system description, the island electricity distribution network is presented in Fig. 3. It is a very robust $15 \mathrm{kV}$ medium voltage (MV) grid, whose consumption is fed by a hydro and a thermal power plant located in bus 1 (swing bus) and a wind farm connected in bus 19. As this grid commonly does not experience low voltage problems, the specified voltage in the swing bus is usually set to 1.03 p.u.. Nevertheless, in case that such problem occurs, there is the possibility to set the voltage value to 1.05 p.u., only by adjusting the step-up transformer taps.

Table 1

Flores island characterization in terms of population and vehicle fleet.

\begin{tabular}{|c|c|c|c|c|c|c|c|c|c|}
\hline \multirow[t]{2}{*}{ Island of flores } & \multicolumn{9}{|l|}{ Year } \\
\hline & 2000 & 2001 & 2002 & 2003 & 2004 & 2005 & 2006 & 2007 & 2008 \\
\hline Population [15] & 3903 & 3904 & 3949 & 3967 & 3991 & 4023 & 4059 & 4099 & 4117 \\
\hline \multicolumn{10}{|c|}{ Type of vehicle [16] } \\
\hline LDV & 971 & 1379 & 1683 & 1914 & 2018 & 2106 & 2181 & 2213 & 2049 \\
\hline HDV + buses & 52 & 57 & 61 & 51 & 51 & 53 & 56 & 57 & 59 \\
\hline
\end{tabular}




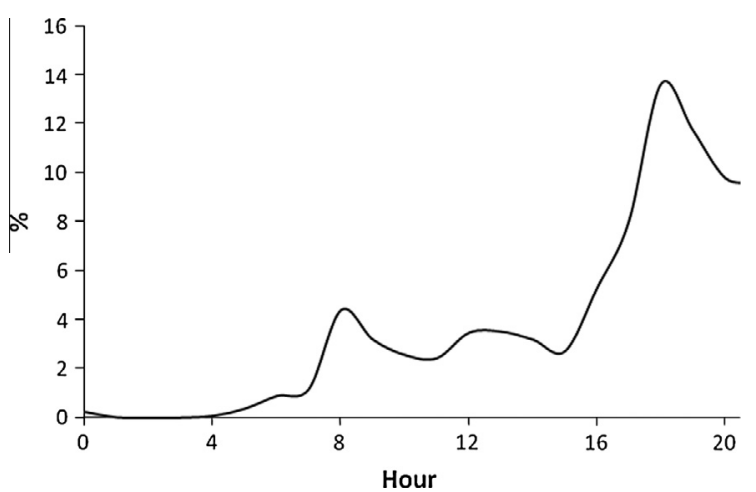

Fig. 2. Percentage of vehicles arriving home from their last daily journey [19].

As it was previously mentioned, the generation system is composed by a hydro power plant with three units of $330 \mathrm{~kW}$ and one of $640 \mathrm{~kW}$, by a thermal power plant with four units of $500 \mathrm{~kW}$ and by a wind farm with two wind turbines of $300 \mathrm{~kW}$ each [20]. The total installed power is $4230 \mathrm{~kW}, 53 \%$ of which comes from Renewable Energy Sources. In normal operating conditions the network is prepared to absorb all the energy produced by the renewable generation units, being the thermal power plant used only to fulfill the remaining energy needs not satisfied by the RES units and to improve the system dynamic behavior.

The network summer and winter typical load diagrams are presented in Fig. 4 [20]. The summer peak load is $1820 \mathrm{~kW}$ and occurs at $22 \mathrm{~h}$ and the winter peak is $1965 \mathrm{~kW}$ and takes place at $19 \mathrm{~h}$. The summer load diagram was obtained through the analysis of the en-

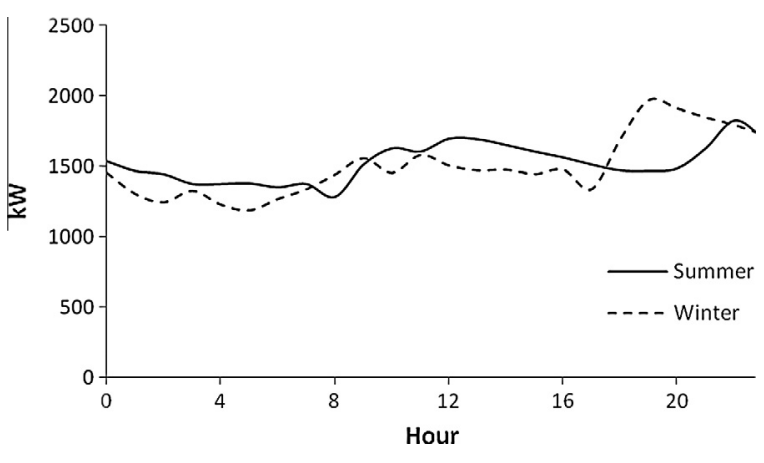

Fig. 4. Summer and winter typical load diagrams.

ergy demand during the period running from April to September. For the winter load diagram data from October to March was used.

Although monthly average load diagrams could have been used, only typical diagrams for summer and winter were considered since the yearly energy demand pattern in the island only undergoes significant changes from the hottest to the coldest months. Additionally, as the summer and winter load diagrams were obtained from the average of the periods running from April to September and from October to March, respectively, it is ensured that the most relevant characteristics of the energy demand pattern in the island are considered in the simulations performed.

In 2009 the island total electric energy consumption was 11.87 GWh from which $5.93 \mathrm{GWh}$ was consumed during the summer period and $5.94 \mathrm{GWh}$ during the winter. Fig. 5 shows the share of electric energy produced in 2009 by type of power plant [21].

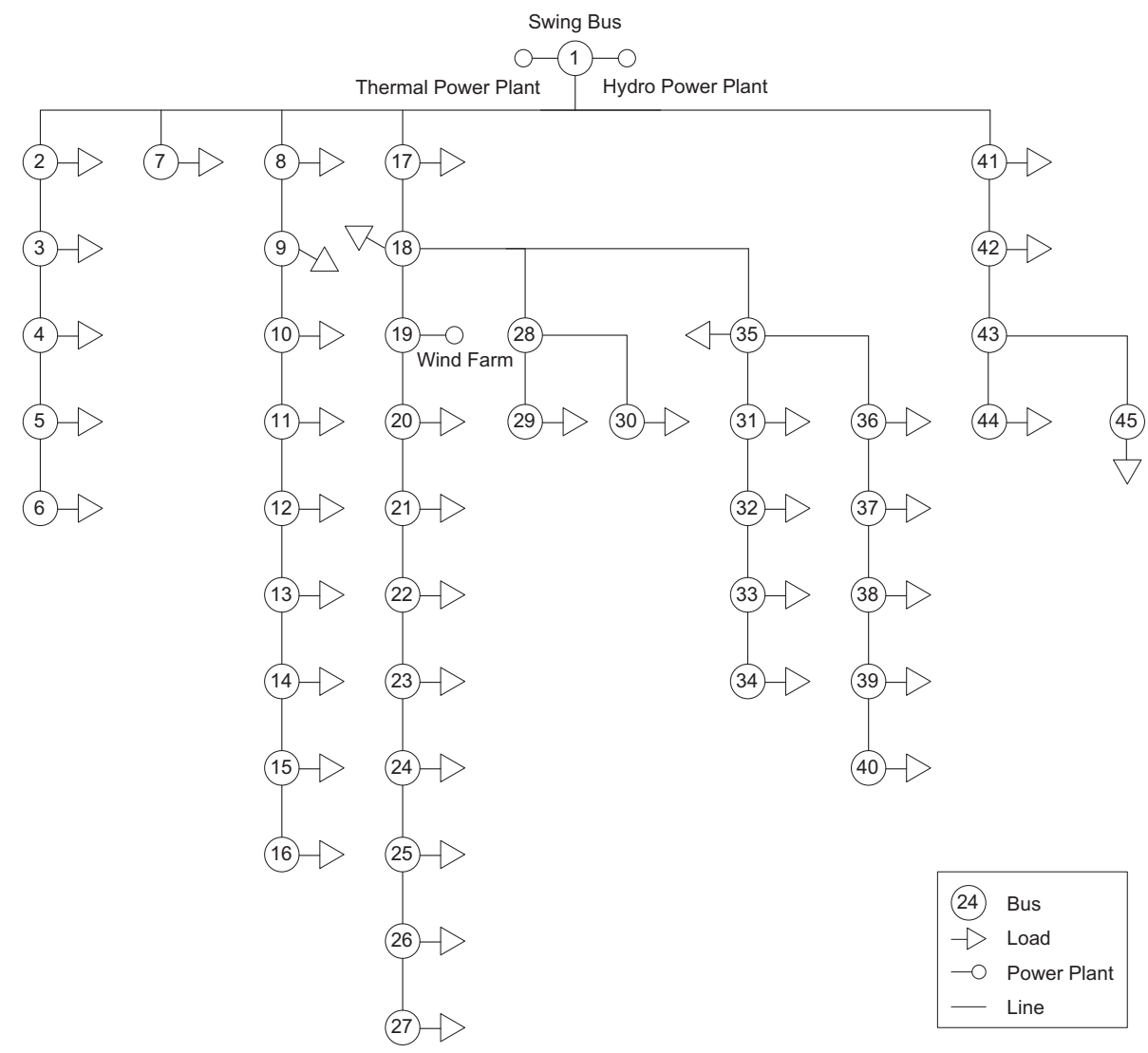

Fig. 3. Medium voltage distribution network (15 kV). 


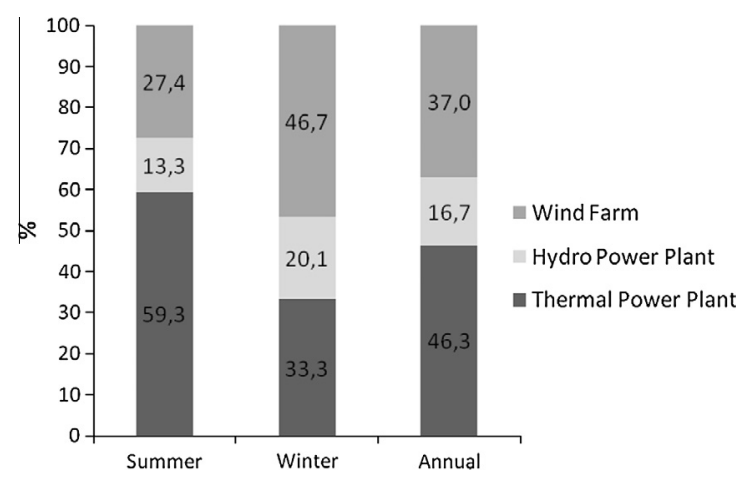

Fig. 5. Share of energy produced in 2009 by type of power plant.

According to EDA [21], the utility company from the Azores, 2009 electricity mix presented in Fig. 5 yields an average emission factor of $364 \mathrm{~g} \mathrm{CO}_{2} / \mathrm{kWh}$.

\section{Methodology}

\subsection{Fleet model}

To assess the impacts of alternative vehicle technologies and energy sources in the fleet of the island of Flores, PATTS (Projections for Alternative Transportation Technologies Software) simulation tool was used. This package was developed "in-house" having the great advantage of a fully knowledge of in-use parameters and representing Portuguese fleet particularities [22,23]. PATTS considers the fleet evolution along time, the vehicle stock (considering not only entries in the market, but also vehicle exists) and the fleet kilometers traveled. Combining this data with the vehicles' fuel consumption (FC) and emissions (according to the vehicle technology/fuel configuration), the total fleet energy consumption and emissions are estimated for the fleet of Flores along the time, as can be observed in Fig. 6 .

The model is capable of tracking a wide variety of variables such as new vehicle sales, market shares of different propulsion systems and their fuel consumption, vehicle aging and scrappage curves, vehicle stock and fuel mixes. Historic data starting from 1973 was used to calibrate the model. When specific data on the Azores or specifically on the island of Flores was available it was used, otherwise average Portuguese fleet values were assumed.

Other than motorization curves [17] that define the trends in the fleet growth, scrappage curves (representing the probability of vehicle breakdown before the planned technical lifetime, the probability of car wreckage and the probability of a car being replaced by a new or used car) were assumed. The values that define

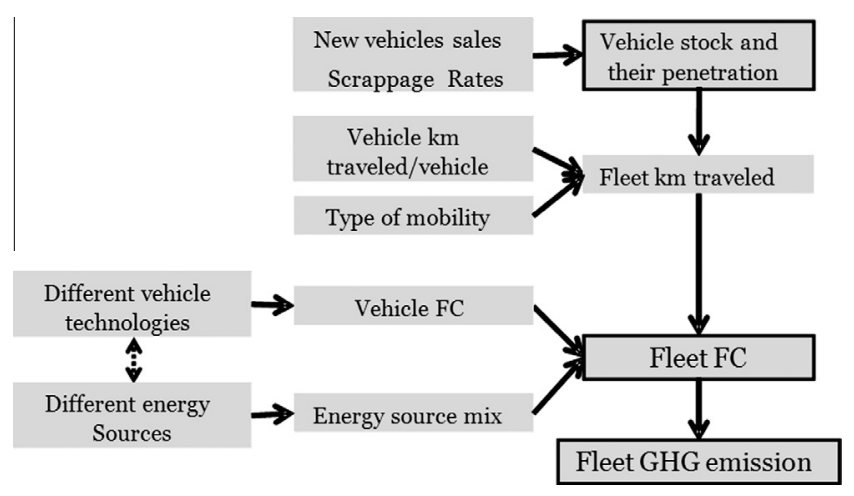

Fig. 6. PATTS overview. scrappage curves are the failure steepness and the characteristic service lifetime for vehicle type: the values given to the Portuguese fleet were 11 and 33 respectively $[17,24]$.

These scrappage curves were applied to all vehicles entering the market since 1973 to the present. Vehicle sales for the future were assumed to have a $1 \%$ growth [25] according to last year's trend. This means that for each year, the number of cars introduced in the market is distributed for the next 30 years into the future, according to its probability of survival. That was done for the historic LDV sales from 1973 to 2008. All new technologies entering the market were attributed a scrappage curve. Gasoline based technologies were assumed to have the conventional gasoline curve and the same for diesel based technologies. Other alternative technologies were assumed to behave similarly to the conventional technologies, therefore its scrappage curve was assumed to be an average between the gasoline and diesel ones.

Regarding the VKT values mentioned previously, the rate of growth in per-vehicle kilometers traveled is assumed to decrease from $0.5 \%$ per year between 2005 and 2020 , to $0.25 \%$ per year in period $2021-2030$, to $0.1 \%$ per year in years after 2030 [26].

For assessing the impact of the different vehicle technologies on the light-duty fleet energy consumption and emissions in a full LCA analysis (see Table 4), the following representative vehicles were considered [7,27-29]:

- ICEV (gasoline or with biofuels blends): internal combustion engine vehicle that can run with gasoline and blends of gasoline and ethanol, with a four cylinder explosion engine with $63 \mathrm{~kW}$ of power and total weight of $1139 \mathrm{~kg}$.

- ICEV (diesel or with biofuels blends): internal combustion engine vehicle that can run with diesel and blends of diesel and biodiesel, with a four cylinder Diesel engine with $67 \mathrm{~kW}$ of power and total weight of $1210 \mathrm{~kg}$.

- PHEV (gasoline or with biofuels blends): plug-in hybrid electric vehicle that can work with gasoline, blends of gasoline and ethanol and electricity. $53 \mathrm{~kW}$ internal explosion combustion engine/generator, $75 \mathrm{~kW}$ electric motor, Ni-MH $15 \mathrm{kWh}$ battery (dischargeable to $45 \%$ of its capacity), series technology with a total weight of $1323 \mathrm{~kg}$.

- PHEV (diesel or with biofuels blends): plug-in hybrid electric vehicle that can work with diesel and blends of diesel and biodiesel and electricity. $53 \mathrm{~kW}$ internal diesel combustion engine/ generator, $75 \mathrm{~kW}$ electric motor, Ni-MH $15 \mathrm{kWh}$ battery, series technology with a total weight of $1323 \mathrm{~kg}$.

- HEV (gasoline): hybrid electric vehicle with parallel and series technology, $43 \mathrm{~kW}$ internal explosion combustion engine, $31 \mathrm{~kW}$ electric motor, Ni-MH 2 battery, $15 \mathrm{~kW}$ generator and $1332 \mathrm{~kg}$.

- EV1 and EV2 (100\% electricity): pure electric vehicle with a $75 \mathrm{~kW}$ electric motor, Ni-MH of 12 and $24 \mathrm{kWh}$ battery capacity, and a total weight of 1214 and $1393 \mathrm{~kg}$ respectively for EV1 and EV2.

Table 3 shows in summary the characteristics of each electricity powered vehicle technology considered in this study. These values are based on the characteristics of the GM Volt/Opel Ampera, Nissan Leaf and Tata Nano drivetrains.

All the vehicles have a total power-to-weight ratio of $55 \mathrm{~W} / \mathrm{kg}$ since this is representative of the top sales of new vehicles sold in Portugal, with which these new technologies will probably have to compete when they start penetrating the market. Additionally, it guarantees that similar vehicle performances are being compared.

The fuels used were gasoline, diesel, ethanol from sugar beet (with an average between pulp to heat process and animal feed export), biodiesel [30,31] (an average between biodiesel from rapeseed, sunflower, rapeseed and blends) and electricity. The 
Table 3

Characteristics of each electricity powered vehicle technology.

\begin{tabular}{|c|c|c|c|c|c|c|c|c|c|c|}
\hline Vehicle & $\begin{array}{l}\text { Battery } \\
\text { type }\end{array}$ & $\begin{array}{l}\text { Battery } \\
\text { capacity } \\
(\mathrm{kW} \text { h) }\end{array}$ & $\begin{array}{l}\text { Charging rated } \\
\text { power }(\mathrm{kW})\end{array}$ & $\begin{array}{l}\text { Electric } \\
\text { motor }(\mathrm{kW})\end{array}$ & $\begin{array}{l}\mathrm{ICE} \\
(\mathrm{kW})\end{array}$ & $\begin{array}{l}\text { Generator } \\
(\mathrm{kW})\end{array}$ & $\begin{array}{l}\text { Total } \\
\text { weight } \\
(\mathrm{kg})\end{array}$ & $\begin{array}{l}\text { Range } \\
(\mathrm{km})\end{array}$ & $\begin{array}{l}\text { Time between } \\
\text { charges (days) }\end{array}$ & $\begin{array}{l}\text { Energy required/ } \\
\text { charge }(\mathrm{kW} h)\end{array}$ \\
\hline $\begin{array}{r}\text { Gasoline } \\
\text { PHEV }\end{array}$ & $\mathrm{NiMH}$ & 6 & 1.5 & 60 & 40 & 40 & 1120 & 30 & 1 & 3.3 \\
\hline $\begin{array}{l}\text { Diesel } \\
\text { PHEV }\end{array}$ & & 6 & 1.5 & 60 & 40 & 40 & 1120 & 30 & 1 & 3.3 \\
\hline $\begin{array}{r}\text { Small EV } \\
(\text { EV1) }\end{array}$ & & 12 & 3 & 65 & - & - & 1214 & 75 & 2 & 10.9 \\
\hline $\begin{array}{r}\text { Large EV } \\
(\mathrm{EV} 2)\end{array}$ & & 24 & 6 & 75 & - & - & 1393 & 150 & 4 & 22.4 \\
\hline
\end{tabular}

Table 4

Energy consumption and $\mathrm{CO}_{2}$ emissions factors applied to each vehicle technology.

\begin{tabular}{|c|c|c|c|c|c|c|}
\hline \multirow[t]{2}{*}{ Vehicle } & \multicolumn{2}{|l|}{ Materials CTG } & \multicolumn{2}{|l|}{ WTT } & \multicolumn{2}{|l|}{ TTW } \\
\hline & Energy (MJ/km) & $\mathrm{CO}_{2}(\mathrm{~g} / \mathrm{km})$ & Energy (MJ/MJ) & $\mathrm{CO}_{2}(\mathrm{~g} / \mathrm{MJ})$ & Energy (MJ/km) & $\mathrm{CO}_{2}(\mathrm{~g} / \mathrm{km})$ \\
\hline ICEV gasoline & 0.48 & 30.7 & 0.14 & 13 & 2.12 & 154 \\
\hline ICEV diesel & 0.50 & 32.0 & 0.16 & 14 & 1.96 & 146 \\
\hline ICEV E100 & 0.48 & 30.7 & 1.58 & 44 & 2.12 & 0 \\
\hline ICEV B100 & 0.50 & 32.0 & 0.94 & 31 & 1.86 & 0 \\
\hline HEV gasoline & 0.58 & 37.7 & 0.14 & 13 & 1.67 & 120 \\
\hline HEV diesel & 0.58 & 37.7 & 0.16 & 14 & 1.54 & 115 \\
\hline EV (electricity) & 0.77 & 47.8 & 0.91 (elect.) & 112 (elect.) & 0.60 & 0 \\
\hline \multirow[t]{2}{*}{ PHEV gasoline } & 0.70 & 43.7 & 0.14 (gas.) & 13 (gas.) & 1.80 & 129 \\
\hline & & & 1.91 (elect.) & 112 (elect.) & 1.12 & 0 \\
\hline \multirow[t]{2}{*}{ PHEV diesel } & 0.70 & 43.8 & 0.16 (die.) & 14 (die.) & 1.66 & 119 \\
\hline & & & 1.91 (elect.) & 112 (elect.) & 1.04 & 0 \\
\hline HDV & 2.52 & 161.0 & 0.16 & 14 & 10.58 & 792 \\
\hline Bus & 3.03 & 193.6 & 0.16 & 14 & 12.76 & 955 \\
\hline Bus NG & 3.33 & 213.0 & 0.12 & 5.5 & 16.33 & 977 \\
\hline Bus $\mathrm{H}_{2}$ & 4.39 & 292.7 & $0.57\left(\mathrm{H}_{2}\right)$ & $88\left(\mathrm{H}_{2}\right)$ & 17.23 & 0 \\
\hline
\end{tabular}

vehicles were simulated in ADVISOR [32] for in-use TTW values. WTT values based on a study by Concawe [31], and Materials CTG were based on the GREET software [33]. Moreover, these values can be found in other publications [23] with slight modifications due to the considered year in analysis.

For the past vehicle fuel consumption and $\mathrm{CO}_{2}$ emissions, the European average historic vehicle fuel consumption (and respective emissions) was assumed [34]. For the future evolution of gasoline, diesel and hybrid Portuguese based technologies, future technological improvements were simulated obtaining reduction potentials up to $40 \%$ in 2050 accordingly [12,22]. For HDV and Buses a potential $20 \%$ and $10 \%$ reduction on fuel consumption is considered until $2050[35,36]$.

Having as a basis the tank-to-wheel (TTW) results, the LCA methodology is applied [7] in order to obtain the well-to-tank (WTT) and cradle-to-grave (CTG) components. The LCA of a vehicle technology powered by a specific fuel must include not only its utilization stage (TTW), related to driving the vehicle, but also the fuel production stage (WTT) and the manufacturing/maintenance/recycling (CTG) of the vehicle itself.

Regarding the electricity WTT, historic data from EDA [21] was used to know the expended energy and emissions of $\mathrm{CO}_{2}$ resulting from the electricity production (see Figs. 5 and 9).

\subsection{Scenarios description}

In order to assess the impact of electricity powered vehicles in the island of Flores three different vehicle technologies and energy source scenarios were studied. The island of Flores is assumed to follow the Portuguese trends in terms of alternative road transportation technology or energy sources, because deploying these alternative technologies/energy sources only makes sense in the Portuguese larger framework. Scenario 1 is a baseline trend sce- nario used as a reference. Scenarios 2 and 3 have increasing penetration of electricity powered vehicles in vehicle sales in the 20102050 timeframe. A brief description of each scenario assumption is presented next.

Scenario 1 - Baseline trend (new vehicle sales mix in Fig. 7). Flores maintains the same liquid fuels based infrastructure and the alternative fuels targets of the Portuguese government for 2020 and 2050 are attained (10\% biodiesel in 2020 [6] and 25\% in 2050 [5] growing at a linear pace). Hybrid technology displaces a small percentage of the total fleet and HEV sales peaks at around $8 \%$ in 2020 stabilizing in that value until 2050. The ratio between the diesel HEV and the gasoline HEV stabilizes at 75/25, following current new vehicle sales trends [25].

Scenario 2 - Policy oriented (new vehicle sales mix in Fig. 7). Flores maintains the liquid fuels based infrastructure but simultaneously develops an infrastructure to facilitate the PHEV and EV charging. As in the first scenario, the alternative fuels targets of the Portuguese government for 2020 and 2050 are met (10\% biodiesel in 2020 [6] and 25\% in 2050 [5] growing at a linear pace). In this scenario $10 \%$ of vehicles sales in 2020 (according to the PME [6]) will be electricity driven ones, with a 70/30 ratio between EV and PHEV. The EV market will stabilize at $10 \%$ in 2050, whereas the PHEV will reach $20 \%$. The HEV will achieve a $15 \%$ market share in 2050 [5] and the ratio between the diesel and the gasoline HEV plus PHEV fleet stabilizes at 75/25.

Scenario 3 - Electricity powered (new vehicle sales mix in Fig. 7). The third scenario is far more optimistic than the previous. It is assumed that a mature and large scale infrastructure is developed and implemented to make possible PHEV and EV charging, making electricity the main energy source for road transportation. The assumptions regarding alternative fuels are the same as in the previous scenarios. In $205090 \%$ of vehicles sales will be electricity influenced (similarly to the EV IEA scenario [36]), with HEV, PHEV 

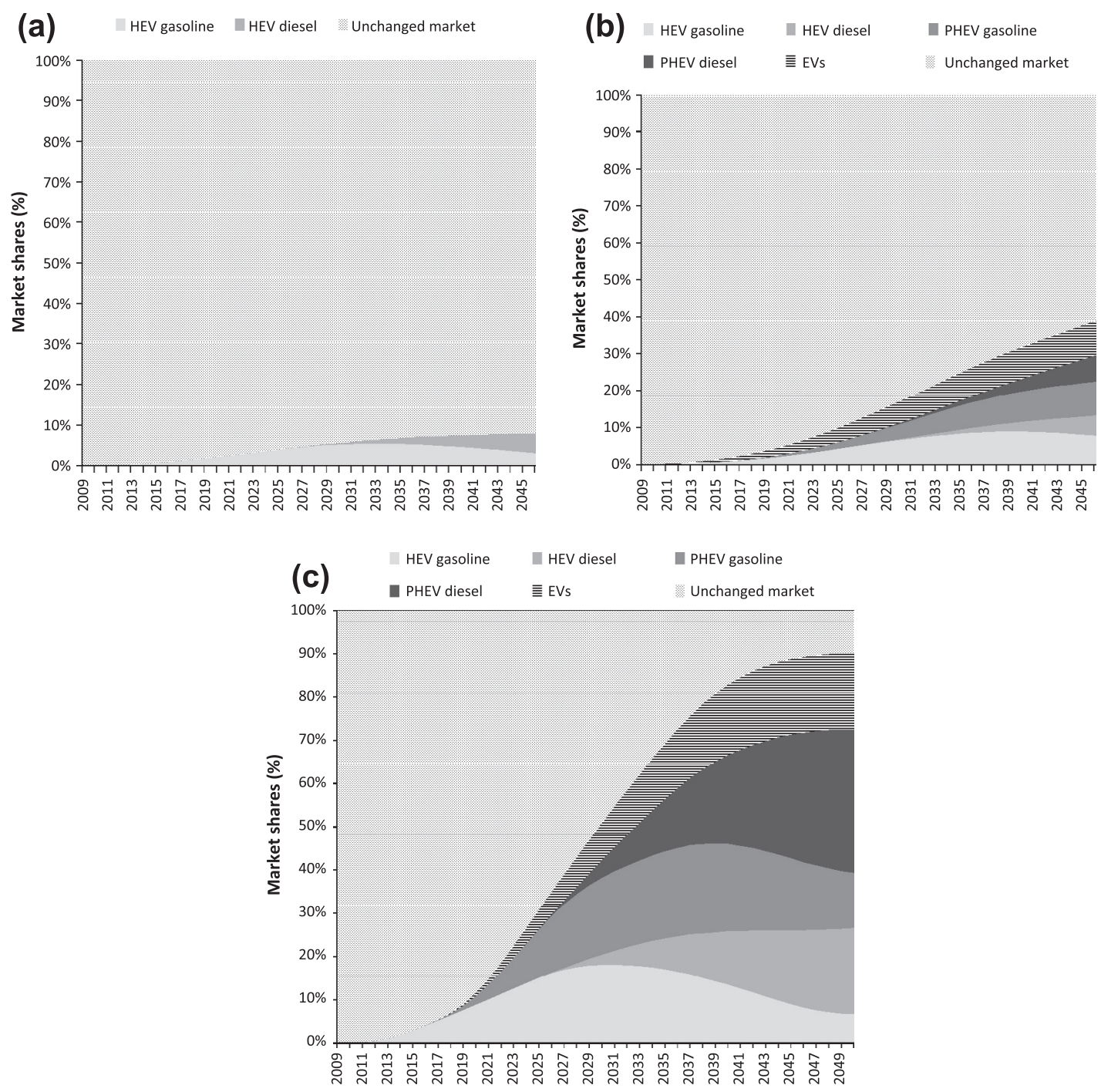

Fig. 7. Island's vehicles sales evolution for Scenario 1 (a), Scenario 2 (b) and Scenario 3 (c).

Table 5

Number and type of vehicles per scenario.

\begin{tabular}{|c|c|c|c|c|c|c|c|c|c|c|}
\hline Vehicles sales evolution & Year & LDV gasoline & LDV diesel & HEV gasoline & HEV diesel & PHEV gasoline & PHEV diesel & Small EV & Large EV & Total \\
\hline- & 2009 & 1341 & 777 & 2 & - & - & - & - & - & 2120 \\
\hline \multirow[t]{2}{*}{ Scenario 1} & 2020 & 876 & 1335 & 51 & - & - & - & - & - & 2262 \\
\hline & 2050 & 536 & 1655 & 62 & 136 & - & - & - & - & 2389 \\
\hline \multirow[t]{2}{*}{ Scenario 2} & 2020 & 866 & 1293 & 46 & - & 10 & - & 23 & 22 & 2260 \\
\hline & 2050 & 347 & 1057 & 163 & 174 & 207 & 231 & 114 & 114 & 2407 \\
\hline \multirow[t]{2}{*}{ Scenario 3} & 2020 & 824 & 1172 & 202 & - & 46 & - & 9 & 8 & 2261 \\
\hline & 2050 & 60 & 182 & 165 & 485 & 311 & 809 & 213 & 213 & 2438 \\
\hline
\end{tabular}

and EV having sales shares of $30 \%, 50 \%$ and $20 \%$, respectively. Once again, the ratio between the diesel and the gasoline HEV plus PHEV fleet stabilizes at 75/25.

\section{Results}

\subsection{Fleet characterization and TTW results}

For Portugal, 2020 and 2050 are the most important dates in the time interval considered in Fig. 7, since they correspond to the Portuguese government commitment dates of alternative fuels consumption, amount of energy provided by $\mathrm{RES}, \mathrm{CO}_{2}$ emissions reduction and energy efficiency increase. Thus, taking this into account, the scenarios analyzed in more detail in this study are referred to the years 2020 and 2050. Additionally, the island current situation was also analyzed in order to provide a comparison basis. Table 5 encloses the number and type of vehicles considered in each scenario given by PATTS, as a result of applying to all the Scenarios new vehicle sales options presented in Fig. 7.

Regarding the network impact evaluation, it makes sense only to analyze scenarios where PHEV or EV are present, as only these vehicles lead to changes in the grid operating conditions due to the energy they require from it. Therefore just Scenarios 2 and 3 were studied in the network impact evaluation section. 
Table 6

TTW energy consumption per type of vehicle for the considered scenarios in Flores.

\begin{tabular}{|c|c|c|c|c|c|c|c|c|c|c|}
\hline $\begin{array}{l}\text { TTW energy consumption (TJ) per vehicle } \\
\text { technology }\end{array}$ & Year & $\begin{array}{l}\text { LDV } \\
\text { gasoline }\end{array}$ & $\begin{array}{l}\text { LDV } \\
\text { diesel }\end{array}$ & $\begin{array}{l}\mathrm{HEV} \\
\text { gasoline }\end{array}$ & $\begin{array}{l}\text { HEV } \\
\text { diesel }\end{array}$ & $\begin{array}{l}\text { PHEV } \\
\text { gasoline }\end{array}$ & $\begin{array}{l}\text { PHEV } \\
\text { diesel }\end{array}$ & $\begin{array}{l}\text { Small } \\
\text { EV }\end{array}$ & $\begin{array}{l}\text { Large } \\
\text { EV }\end{array}$ & Total \\
\hline & 2009 & 17.06 & 50.93 & 0.06 & - & - & - & - & - & 68.06 \\
\hline & 2009 & 17.06 & 50.93 & 0.06 & - & - & - & - & - & 68.06 \\
\hline \multirow[t]{2}{*}{ Scenario 1} & 2020 & 12.53 & 77.80 & 1.00 & - & - & - & - & - & 91.33 \\
\hline & 2050 & 9.54 & 85.21 & 1.09 & 3.06 & - & - & - & - & 98.90 \\
\hline \multirow[t]{2}{*}{ Scenario 2} & 2020 & 12.53 & 77.80 & 1.00 & - & 0.08 & - & 0.14 & 0.14 & 91.69 \\
\hline & 2050 & 6.06 & 54.01 & 2.88 & 4.12 & 0.16 & 3.99 & 0.43 & 0.43 & 72.09 \\
\hline \multirow[t]{2}{*}{ Scenario 3} & 2020 & 11.08 & 67.28 & 4.48 & - & 0.38 & - & 0.06 & 0.06 & 83.34 \\
\hline & 2050 & 1.06 & 9.35 & 2.87 & 10.72 & 0.24 & 13.12 & 0.81 & 0.81 & 38.98 \\
\hline
\end{tabular}

Table 7

$\mathrm{CO}_{2}$ emissions per type of vehicle for the considered scenarios in Flores.

\begin{tabular}{|c|c|c|c|c|c|c|c|c|c|c|}
\hline $\begin{array}{l}\text { TTW } \mathrm{CO}_{2} \text { emissions (kton) per vehicle } \\
\text { technology }\end{array}$ & Year & $\begin{array}{l}\text { LDV } \\
\text { gasoline }\end{array}$ & $\begin{array}{l}\text { LDV } \\
\text { diesel }\end{array}$ & $\begin{array}{l}\text { HEV } \\
\text { gasoline }\end{array}$ & $\begin{array}{l}\text { HEV } \\
\text { diesel }\end{array}$ & $\begin{array}{l}\text { PHEV } \\
\text { gasoline }\end{array}$ & $\begin{array}{l}\text { PHEV } \\
\text { diesel }\end{array}$ & $\begin{array}{l}\text { Small } \\
\text { EV }\end{array}$ & $\begin{array}{l}\text { Large } \\
\text { EV }\end{array}$ & Total \\
\hline & 2009 & 1.23 & 3.81 & 0.00 & - & - & - & - & - & 5.04 \\
\hline & 2009 & 1.23 & 3.81 & 0.00 & - & - & - & - & - & 5.04 \\
\hline \multirow[t]{2}{*}{ Scenario 1} & 2020 & 0.90 & 5.60 & 0.07 & - & - & - & - & - & 6.57 \\
\hline & 2050 & 0.69 & 5.09 & 0.08 & 0.23 & - & - & - & - & 6.08 \\
\hline \multirow[t]{2}{*}{ Scenario 2} & 2020 & 0.90 & 5.60 & 0.07 & - & 0.001 & - & 0.00 & 0.00 & 6.57 \\
\hline & 2050 & 0.44 & 3.23 & 0.21 & 0.31 & 0.003 & 0.06 & 0.00 & 0.00 & 4.24 \\
\hline \multirow[t]{2}{*}{ Scenario 3} & 2020 & 0.80 & 4.87 & 0.32 & - & 0.007 & - & 0.00 & 0.00 & 6.00 \\
\hline & 2050 & 0.08 & 0.56 & 0.21 & 0.81 & 0.004 & 0.19 & 0.00 & 0.00 & 1.85 \\
\hline
\end{tabular}

In the section of environment impact evaluation all the scenarios were analyzed as the objective was to assess the $\mathrm{CO}_{2}$ emissions and the primary energy consumption of the entire fleet. Tables 6 and 7 present the energy consumption and $\mathrm{CO}_{2}$ emissions per type of vehicle. If no major changes are performed (Scenario 1) comparing 2009-2050 energy consumption will rise by $45 \%$ and $\mathrm{CO}_{2}$ emissions by $21 \%$, due to the growing demand for energy in transportation. In 2050, if Scenarios 2 and 3 are considered the decrease of TTW energy consumption and $\mathrm{CO}_{2}$ emissions is of $30 \%$ and 70\% respectively compared to Scenario 1 .

Additionally, the TTW energy consumption profiles per energy source are presented for the three Scenarios (see Fig. 8). For Scenario 2, electricity accounts in 2050 for $3.91 \mathrm{TJ}$ which corresponds to $5 \%$ of the total energy consumption of LDVs. As for Scenario 3 in 2050 that value reaches $11.42 \mathrm{TJ}$ which corresponds to $29 \%$ of the total energy consumption.

Taking into account the additional layer of HDV, an average $39 \%$ energy consumption and $48 \% \mathrm{CO}_{2}$ emissions share is added to all LDV scenarios in terms of the TTW stage, as is presented in Table 11.

\subsection{Network impact evaluation and EV charging approaches}

As it was previously referred, only Scenarios 2 and 3 of vehicle sales evolution were studied in this section given that in Scenario 1 there are no EV present in the island. The 2009 situation was also evaluated in order to provide a comparison basis to the results obtained for the other scenarios.

The MV/low voltage (LV) transformers, represented by triangular shapes in Fig. 3, plus the downstream LV grid, were assumed to have the capacity to accommodate all the EV considered in Scenarios 2 and 3 without any problems. This assumption allows focusing the study in the MV grid, as it is intended with this paper.

Regarding EV electric energy demand, a worst case scenario was assumed, where all of them require a full charge during the summer and winter days studied. This is not the most realistic situation but it is a scenario that is worth analyzing given that it provides valuable information about the network's behavior in an extreme case of electricity demand.

To establish a proper comparison between the several created scenarios, the results regarding network impacts were computed using PSS/ETM, and then compiled into several tables and figures that will be presented along the following subsections. A power flow was run for each hour of the summer and winter days considered, taking into account the assumptions made for each scenario.

The EV impact in the grid was studied for two different charging approaches: dumb and smart charging [37]. The dumb charging shall be regarded as a non-control approach, where EV owners are completely free to connect their vehicles to the grid and charge them whenever they want. It is assumed that EV start charging as soon as they are connected to the grid and that they take the following $4 \mathrm{~h}$ to reach a $100 \%$ State-of-Charge (SOC). In the smart charging approach the existence of an aggregator entity is assumed $[38,39]$. In case of necessity, this aggregator entity gathers information from all the EV under its domain that are willing to provide system services. If some problem appears in the grid, the Distribution System Operator (DSO), who continuously monitors the grid operating conditions, determines the adjustments in the EVs load that are required to solve the problem and asks the aggregators to manage the EVs charging accordingly. Then the aggregator will require from EV the system services bought by the DSO, paying them a previously agreed fee. Within this business model the DSO might solve several grid problems such as low voltages, branches' congestion levels and transformers saturation, at least to some extent, or even reduce the peak load and the energy losses in the grid.

Therefore, the smart charging can be regarded as a demand response scheme since EV owners will change their electricity usage from their normal consumption patterns in response to incentive payments from the aggregator, designed to induce lower electricity use at peak load periods or when system reliability is jeopardized.

It should be noted that the smart charging algorithm developed in this work gives priority to the network over the EV owners' requirements when technical problems occur. Thus, it is not guaranteed that EVs are fully charged before leaving home. However, this methodology assures that transformer or line overloading, as well as other technical problems, are promptly solved by adjusting EVs charging rates, never jeopardizing the normal operation of the network.

The algorithm assumes the existence of a bi-directional communication platform that allows a proper data exchange between EV and the aggregator and between the latter and the DSO. It is also 

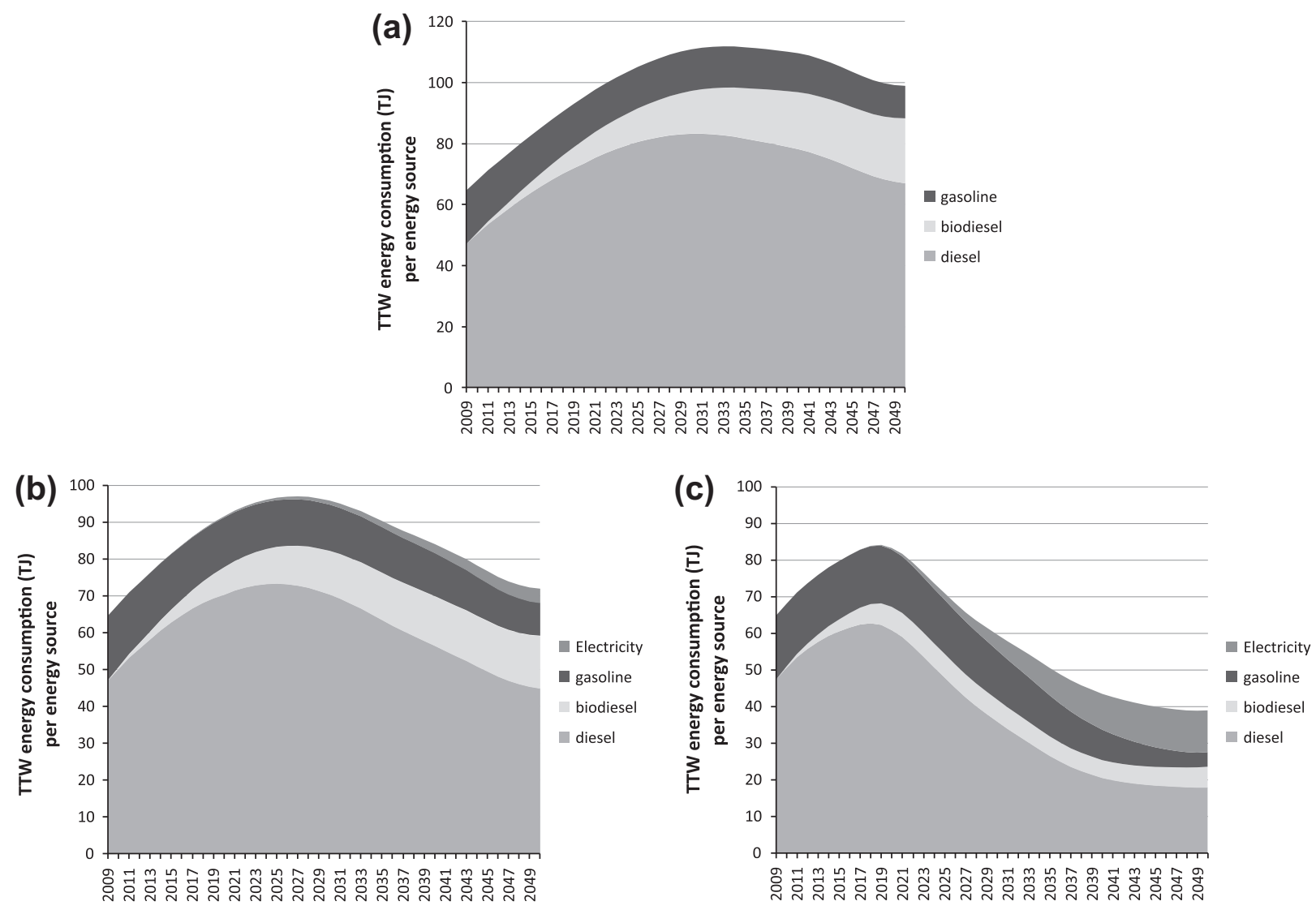

Fig. 8. Scenarios 1, 2 and 3 TTW energy consumption in the 2009-2050 period for the Flores' LDV fleet.

admitted the existence of smart grid functionalities in the network, such as smart meters with bi-directional communication capability, that allow the DSO to have a real-time perception of what is happening in the grid at each moment and purchase system services from the aggregator if such action is needed.

It should be noted that no demand response scheme was considered for the conventional household loads in the network, which were treated in all the scenarios as uncontrollable loads.

\subsection{0 and 2050 generation system, grid energy demand and $\mathrm{CO}_{2}$ emission factor}

In accordance with EDA [21], the expansion plans of the island's generation system until 2020 only refers the construction of a new hydro power plant with two units of $550 \mathrm{~kW}$ each, being the total generation power upgraded to $5330 \mathrm{~kW}(600 \mathrm{~kW}$ wind power; $2000 \mathrm{~kW}$ thermal power; and $2730 \mathrm{~kW}$ hydro power). There are no more reinforcements planned for the period between 2020 and 2050. For this reason the island's generation system was assumed to be the same in 2020 and 2050.

The average load growth in the island was $5.8 \%$ in the past 12 years. However, the political measures implemented and the growing concerns with environmental issues are leading to an increase in energy efficiency, which is verifiable by the decreasing trend that the energy demand is evidencing in the last 4 years [40]. Given all the facts available, an average load growth of 3.0\% per year was assumed as the most probable scenario to occur between 2009 and 2020. For the period from 2020 to 2050, due to the predictable reinforcement of the political measures aiming to increase energy efficiency, an annual energy demand increase of $0.5 \%$ was assumed.
Table 8

Peak load.

\begin{tabular}{lll}
\hline Year & Period & Peak load $(\mathrm{MW})$ \\
\hline \multirow{2}{*}{2009} & Summer & 1.82 \\
& Winter & 1.97 \\
2020 & Summer & 2.52 \\
& Winter & 2.72 \\
2050 & Summer & 2.93 \\
& Winter & 3.16 \\
\hline
\end{tabular}

The shape of the load diagrams in 2020 and 2050 is assumed to be similar to those presented in Fig. 4. However, due to the annual increase of the energy demand, the peak load and the daily energy consumption undergo significant changes. Table 8 shows the peak load for all the scenarios studied. The values presented are the same for the three scenarios of vehicles sales evolution.

Table 9 presents the aggregated daily energy demand of all the $\mathrm{EV}$, as well as the daily consumption from the grids' loads and the total daily energy demand in all the scenarios created (common loads plus EV load). For 2009 and for Scenario 1 there is no additional energy required from EV since they are not present in the grid.

As mentioned previously, the values presented in Tables 8 and 9 are referred to a worst case scenario regarding EV electric energy demand. These values were computed assuming that all EV require a full charge in the summer and winter days analyzed. Although the situation is likely to seldom occur, it is still a scenario that deserves to be studied since it provides valuable information about the network's behavior in an extreme case of electricity demand.

All the values presented, regarding the EV energy demand, were computed taking into account the number and the characteristics of all the EV that were considered in each scenario studied. 
Table 9

Energy requirements from the common loads and from EV.

\begin{tabular}{|c|c|c|c|c|c|}
\hline $\begin{array}{l}\text { Vehicles } \\
\text { sales } \\
\text { evolution }\end{array}$ & Year & Period & $\begin{array}{l}\text { EV daily } \\
\text { energy } \\
\text { demand } \\
\text { (MW h) }\end{array}$ & $\begin{array}{l}\text { Grid daily } \\
\text { energy } \\
\text { demand } \\
\text { (MW h) }\end{array}$ & $\begin{array}{l}\text { Total daily } \\
\text { energy } \\
\text { demand } \\
(\mathrm{MW} \mathrm{h})\end{array}$ \\
\hline \multirow[t]{2}{*}{ - } & \multirow{2}{*}{2009} & Summer & - & 32.49 & 32.49 \\
\hline & & Winter & - & 32.56 & 32.56 \\
\hline \multirow{4}{*}{$\begin{array}{c}\text { Scenario } \\
1\end{array}$} & \multirow{2}{*}{2020} & Summer & - & 44.98 & 44.98 \\
\hline & & Winter & - & 45.07 & 45.07 \\
\hline & \multirow[t]{2}{*}{2050} & Summer & - & 52.24 & 52.24 \\
\hline & & Winter & - & 52.35 & 52.35 \\
\hline \multirow{4}{*}{$\begin{array}{c}\text { Scenario } \\
2\end{array}$} & \multirow[t]{2}{*}{2020} & Summer & 0.88 & 44.98 & 45.86 \\
\hline & & Winter & 0.88 & 45.07 & 45.95 \\
\hline & \multirow[t]{2}{*}{2050} & Summer & 6.73 & 52.24 & 58.97 \\
\hline & & Winter & 6.73 & 52.35 & 59.08 \\
\hline \multirow{4}{*}{$\begin{array}{c}\text { Scenario } \\
3\end{array}$} & \multirow[t]{2}{*}{2020} & Summer & 0.59 & 44.98 & 45.57 \\
\hline & & Winter & 0.59 & 45.07 & 45.66 \\
\hline & \multirow[t]{2}{*}{2050} & Summer & 14.39 & 52.24 & 66.63 \\
\hline & & Winter & 14.39 & 52.35 & 66.74 \\
\hline
\end{tabular}

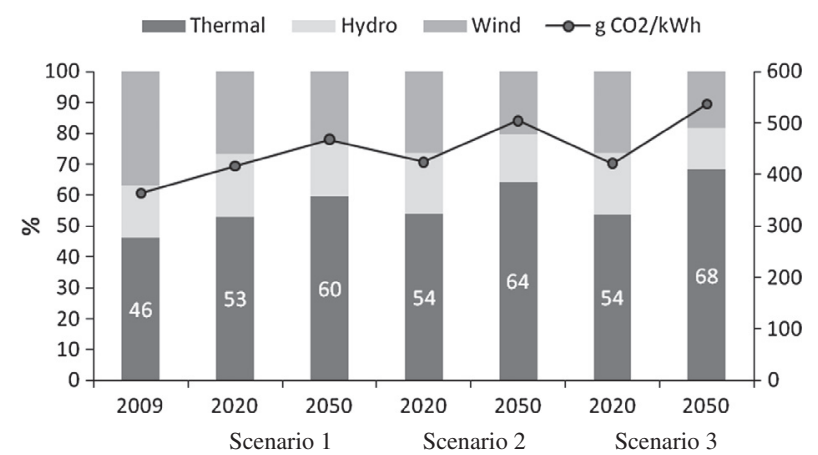

Fig. 9. Share of energy produced by type of power plant and $\mathrm{CO}_{2}$ emissions factor per scenario.

The share of energy produced by the hydro power plant and the wind farm were calculated for the amounts of energy required in each scenario, as presented in Table 9. These values were computed assuming a linear dependence between the installed power and the electricity generated by these sources. The thermal power plant was used to fulfill the remaining energy demand. As the load growth is not accompanied by a significant expansion in the RES power installed, the thermal generation assumes increasing importance in the electricity mix. Fig. 9 shows the share of electric energy produced by type of power plant in all the scenarios, which influences the WTT factor for electricity production in terms of expended energy and $\mathrm{CO}_{2}$ emissions.

Given the fact that in this system all the $\mathrm{CO}_{2}$ emissions are from the thermal power plant, the emissions factor increases proportionally to the share of energy produced by this facility (white values in Fig. 9). The $\mathrm{CO}_{2}$ emissions per kWh for 2020 and 2050 were determined taking as basis the value of $364 \mathrm{~g} / \mathrm{kWh}$ for 2009 [21] The values obtained were $417 \mathrm{~g} \mathrm{CO} / \mathrm{kWh}$ for 2020 and $469 \mathrm{~g}$ $\mathrm{CO}_{2} / \mathrm{kWh}$ for 2050 in the first scenario, $424 \mathrm{~g} \mathrm{CO}_{2} / \mathrm{kWh}$ for 2020 and $505 \mathrm{~g} \mathrm{CO}_{2} / \mathrm{kWh}$ for 2050 in the second scenario and $422 \mathrm{~g}$ $\mathrm{CO}_{2} / \mathrm{kWh}$ for 2020 and $537 \mathrm{~g} \mathrm{CO}_{2} / \mathrm{kWh}$ for 2050 in Scenario 3. These $\mathrm{CO}_{2}$ values were assumed as input to the PATTS simulations of fleet LCA.

The simulation platform developed in this work to run all the simulations intends to reproduce the system operation in the presence of the aggregator and the DSO and their interaction with the EV owners, as described previously.

First the dumb charging approach is put into practice and, by running power flows, the simulation platform continuously evaluates if there are any problems in the grid (featuring DSO). If so, the problem is identified and the smart charging algorithm is trig-

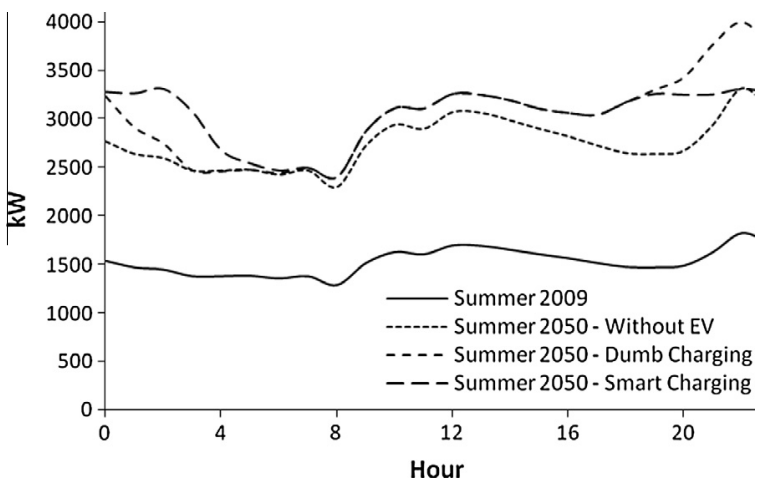

Fig. 10. Load profiles for Scenario 2: summer day in 2009 and in 2050 .

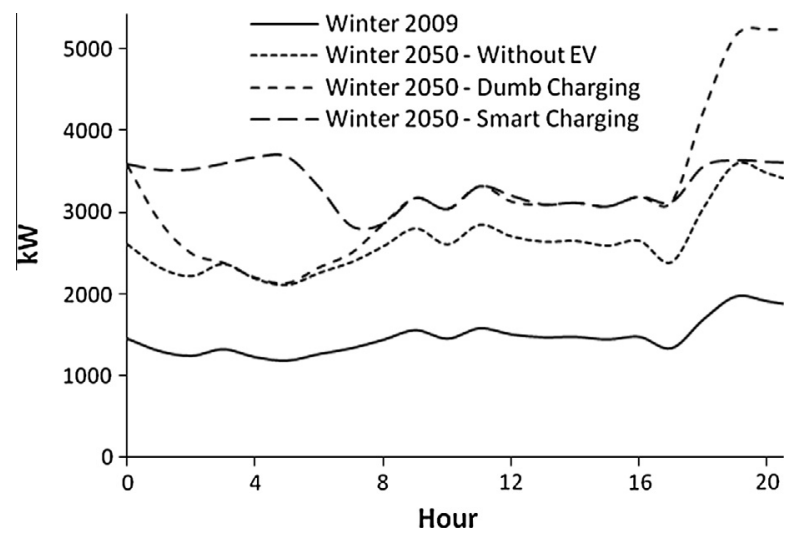

Fig. 11. Load profiles for Scenario 3: winter day in 2009 and in 2050.

gered. Then the smart charging algorithm halt the charging process of a certain number of EV in order to restore the grid's normal operating conditions (simulates the acquisition of a system service by the DSO to EV owners, via the aggregator). The number of EV whose charging is stopped is defined in accordance with the problem severity (only EV that adhered to the smart charging scheme are eligible to stop their charging). These EV resume their charging process as soon as problems are solved (the aggregator will then compensate these EV owners for the services provided).

The load diagrams change due to EV energy consumption and to load increase for the summer day of Scenario 2 and for the winter day of Scenario 3, both for 2050, are presented in Figs. 10 and 11, respectively. Each figure contains four profiles, one for 2009, one for 2050 without EV in the grid and the remaining for both charging approaches considered, dumb and smart charging. The curve of the dumb charging was obtained by restraining the action of the smart charging algorithm in the simulation platform previously described. In such circumstances, even when problems in the network were detected, no control actions whatsoever were taken over EV.

Given the robustness of this network, no major problems were detected during the simulations. Only one slight issue related with low voltages was detected in the year 2050 of Scenarios 2 and 3 but it was promptly solved by increasing the voltage in the swing bus from 1.03 to 1.05 p.u.. The peak load value was the condition that triggered the smart charging algorithm in the situations represented in Figs. 10 and 11. A value was previously defined as the maximum allowed peak load, in each scenario, in order to reduce the need to install extra power generation to fulfill all the consumption. The predefined value was $3350 \mathrm{~kW}$ for Fig. 10 and 


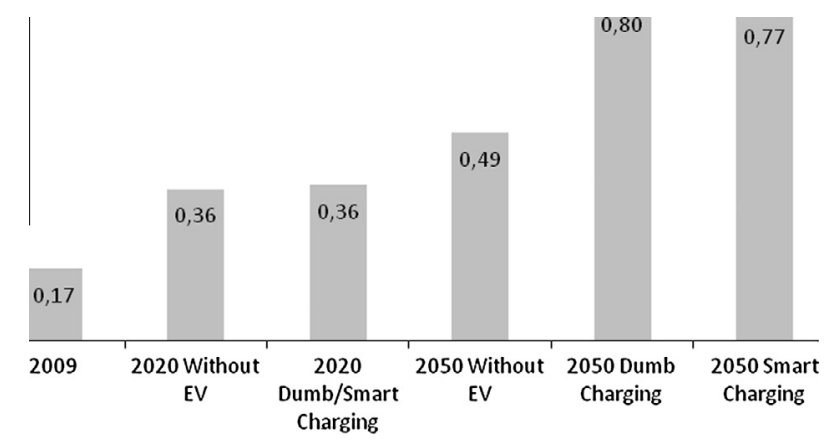

Fig. 12. Yearly losses for 2009 and for 2020 and 2050 of the Scenario 3.

$3675 \mathrm{~kW}$ for Fig. 11. When the load reached these values, the smart charging algorithm was activated, postponing some EV charging towards the night period.

Only the results of the summer day of Scenario 2 and of the winter day of Scenario 3 for 2050 were presented in this section as they are quite similar to the ones obtained for the winter day of Scenario 2 and for the summer day of Scenario 3.

The results for the year 2020 were not presented since the EV integration in the grid was almost imperceptible in terms of load diagram changes, being the smart charging algorithm completely idle during the entire summer and winter days.

\subsection{Energy losses and voltage profiles}

In Fig. 12 the yearly losses in GWh are presented for Scenario 3 of vehicles sales evolution. Additionally the losses in 2009 are also presented to provide a comparison basis.

By analyzing the chart it is possible to infer that the increase in energy consumption due to EV have a much higher impact over losses than the charging approach implemented. Nevertheless, the losses reduction attained with the smart charging, when compared with the dumb charging, should not be neglected. Furthermore, if a specific smart charging algorithm is specifically developed with the objective of minimizing losses, the benefits achieved would certainly be greater.

Losses for Scenario 1 are $0.36 \mathrm{GWh}$ in 2020 and $0.49 \mathrm{GWh}$ in 2050, the same as the values presented in Fig. 12 for the scenarios without EV. For Scenario 2, the losses follow the same trend as in Scenario 3 but with lower values due to the inferior number of EV present in the network. Fig. 12 presents only one result for the dumb and smart charging in 2020 given that the system is capable of handling all the EV without triggering the smart charging algorithm.

In Fig. 13 it is represented the lowest bus voltage of the grid (bus 40 in Fig. 3), for the peak hour of the winter day considered. Only winter day results are presented in this section since the grid operating conditions are more demanding than in the summer day.

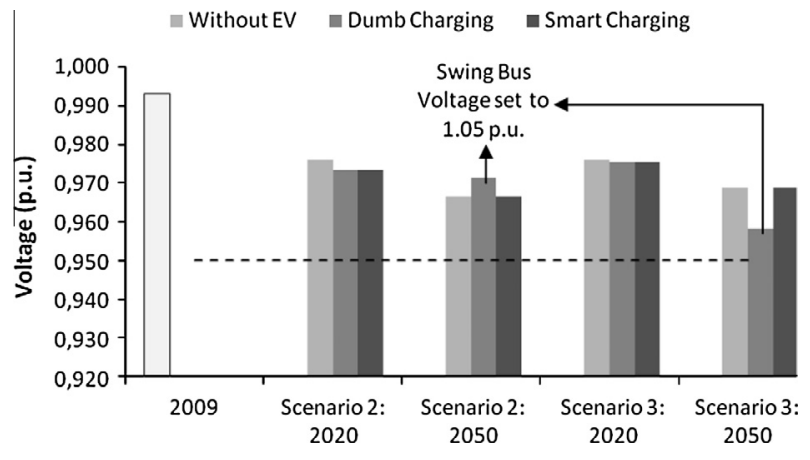

Fig. 13. Lowest bus voltage (bus 40 ) for the winter day.
As previously referred, there are no problems registered for 2020 . However it is clearly noticeable that the extra energy required by $\mathrm{EV}$ induces a general decrease in voltage profiles, both for Scenarios 2 and 3.

For 2050 there are some low voltage problems when the dumb charging approach is implemented, which are easily solved by increasing voltage in the swing bus to 1.05 p.u.. In these circumstances, if the voltage in this bus is kept at 1.03 p.u., the voltage in the worst bus goes below the allowed minimum value of 0.95 p.u. (represented by the dashed line in the chart).

With the smart charging approach this problem does not occur given that by postponing the charging of some EV it is always possible to maintain the worst bus voltage within acceptable values.

\subsection{Branches' congestion levels}

Regarding branches' congestion levels, only results for the peak hour of the winter day are presented for the same reasons stated in the voltage profiles section. The results presented in Fig. 14 confirm the high robustness of the island's network. Even in the more demanding scenario for the grid, the most congested line only reaches $54 \%$ of its total capacity.

In global terms, once again, results prove the effectiveness of the smart charging algorithm when compared with the dumb charging approach. With the smart charging, lines congestion levels are kept almost unchanged when compared to the scenarios without EV due to their charging postponement for the periods where energy demand is lower. However, it should be noted that the smart charging algorithm was activated by a different reason than the line congestion levels. As referred in the load diagrams section, the algorithm was triggered by the peak load constraints.

\subsection{Total fleet life cycle analysis}

After adding the WTT and the Materials CTG contributions to the TTW layer already presented, the full LCA for the fleet of Flores is obtained. All the individual contributions and the global LCA results for the selected years for the LDV fleet are presented in Table 10.

In 2009 , the TTW accounts for $78 \%$ of the energy consumption and $\mathrm{CO}_{2}$ emissions of the total LCA, while the WTT and the CTG correspond to $12 / 14 \%$ and $9 / 8 \%$ for energy consumption $/ \mathrm{CO}_{2}$ emissions. For 2050 in the base case/baseline situation (Scenario 1), the TTW stage accounts for $66 / 67 \%$ of the total LCA (energy $/ \mathrm{CO}_{2}$ ), while WTT accounts for $21 / 19 \%$ and CTG to $13 / 14 \%$ (energy $/ \mathrm{CO}_{2}$ ). If increasing scenarios of electricity powered vehicles are considered (Scenarios 2 and 3), then a shift in energy consumption from the TTW stage to the WTT occurs, so the TTW stage in 2050 for Scenarios 2 and 3 is reduced to $61 / 59 \%$ and $47 / 34 \%$ of the total LCA (energy $/ \mathrm{CO}_{2}$ ). Accordingly, the WTT values increase to $23 / 25 \%$ and $28 / 41 \%$ of the total LCA for Scenarios 2 and 3 (energy $/ \mathrm{CO}_{2}$ ).

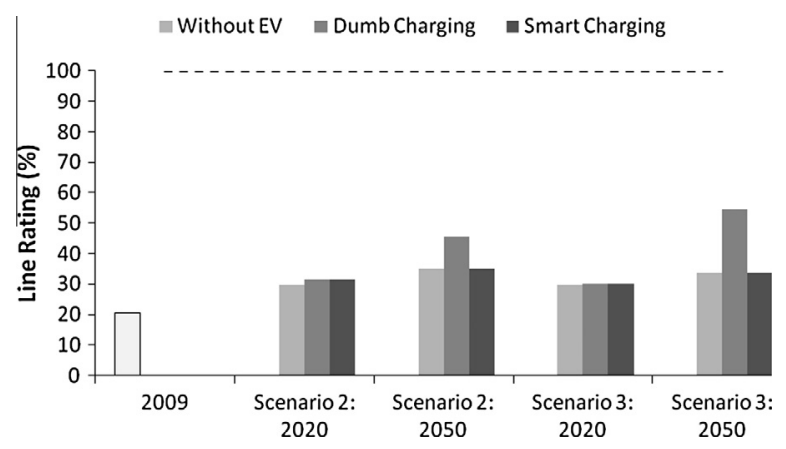

Fig. 14. Most congested line (line from bus 1 to bus 17 ) for the winter day. 
Table 10

LDV LCA energy consumption and $\mathrm{CO}_{2}$ emissions results.

\begin{tabular}{|c|c|c|c|c|c|c|c|c|c|}
\hline \multirow[t]{2}{*}{ LDV } & \multirow[t]{2}{*}{ Year } & \multicolumn{4}{|c|}{ Energy consumption (TJ) } & \multicolumn{4}{|c|}{$\mathrm{CO}_{2}$ emissions (kton) } \\
\hline & & TTW & WTT & CTG & Total & TTW & WTT & CTG & Total \\
\hline & 2009 & 64.82 & 10.02 & 7.80 & 82.64 & 4.80 & 0.89 & 0.50 & 6.19 \\
\hline & 2009 & 64.82 & 10.02 & 7.80 & 82.64 & 4.80 & 0.89 & 0.50 & 6.19 \\
\hline \multirow[t]{2}{*}{ Scenario 1} & 2020 & 95.30 & 21.00 & 12.71 & 129.00 & 6.85 & 1.46 & 0.81 & 9.12 \\
\hline & 2050 & 98.90 & 32.10 & 19.22 & 150.22 & 6.08 & 1.75 & 1.23 & 9.07 \\
\hline \multirow[t]{2}{*}{ Scenario 2} & 2020 & 91.69 & 20.46 & 12.55 & 124.70 & 6.57 & 1.44 & 0.80 & 8.82 \\
\hline & 2050 & 72.09 & 26.44 & 18.98 & 117.50 & 4.24 & 1.78 & 1.21 & 7.23 \\
\hline \multirow[t]{2}{*}{ Scenario 3} & 2020 & 83.34 & 18.36 & 12.20 & 113.90 & 6.00 & 1.31 & 0.78 & 8.09 \\
\hline & 2050 & 38.98 & 23.15 & 21.43 & 83.56 & 1.85 & 2.27 & 1.36 & 5.48 \\
\hline
\end{tabular}

Table 11

HDV LCA energy consumption and $\mathrm{CO}_{2}$ emissions results.

\begin{tabular}{|c|c|c|c|c|c|c|c|c|c|}
\hline \multirow[t]{2}{*}{ HDV } & \multirow[t]{2}{*}{ Year } & \multicolumn{4}{|c|}{ Energy consumption (TJ) } & \multicolumn{4}{|c|}{$\mathrm{CO}_{2}$ emissions (kton) } \\
\hline & & TTW & WTT & CTG & Total & TTW & WTT & CTG & Total \\
\hline \multirow{4}{*}{ Scenarios 1,2 and 3} & 2009 & 28.11 & 4.50 & 5.10 & 37.70 & 2.10 & 0.40 & 0.33 & 2.83 \\
\hline & 2009 & 28.11 & 4.50 & 5.10 & 37.70 & 2.10 & 0.40 & 0.33 & 2.83 \\
\hline & 2020 & 26.58 & 6.22 & 5.57 & 38.38 & 1.95 & 0.42 & 0.36 & 2.72 \\
\hline & 2050 & 26.58 & 8.53 & 6.25 & 41.35 & 1.49 & 0.45 & 0.40 & 2.34 \\
\hline
\end{tabular}
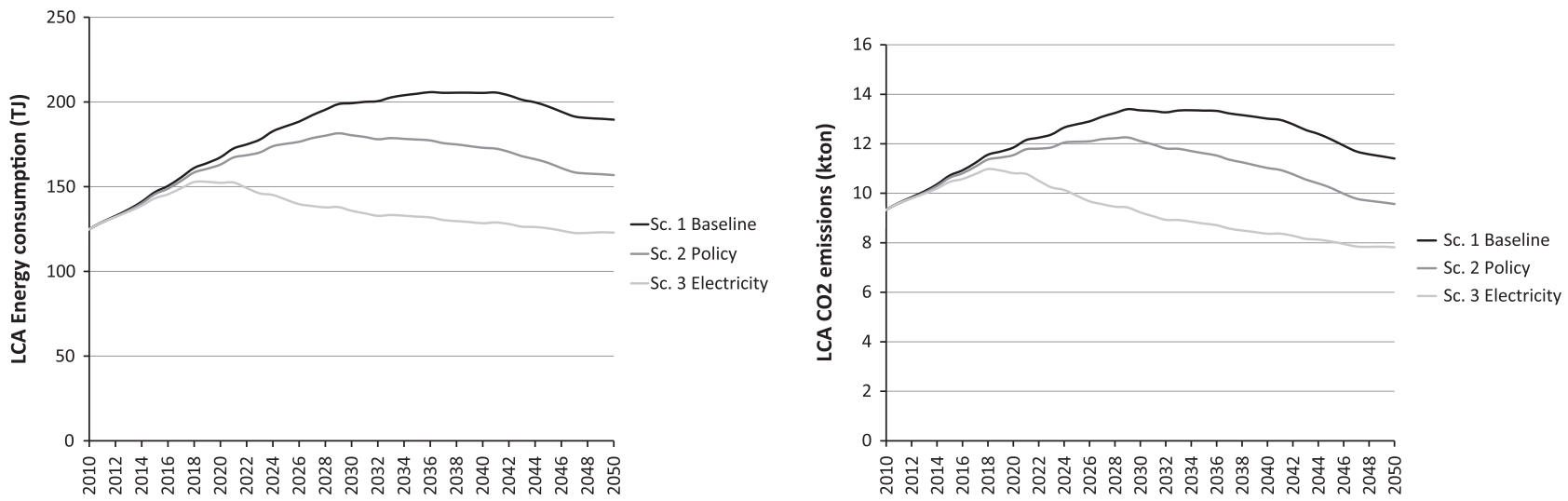

Fig. 15. Scenarios 1, 2 and 3 full LCA energy consumption (TJ) and $\mathrm{CO}_{2}$ emissions (kton) in the 2010-2050 period for the Flores' fleet.

As for the CTG share of the LCA for Scenarios 2 and 3 it reaches 16/ $17 \%$ and $26 / 25 \%$ (energy/ $/ \mathrm{CO}_{2}$ ) since more energy intensive processes are being used to produce the alternative vehicle technologies introduced.

Simultaneously the HDV full LCA was also considered. The HDV contribution for all three scenarios is presented in Table 11 , which demonstrates that, additionally to the TTW increase previously mentioned due to the HDV fleet, the total LCA increase due to HDV considering the three LCA stages accounts for an average $63 \%$ energy consumption and $40 \% \mathrm{CO}_{2}$ emissions.

Finally, the LDV and HDV contributions are added together to have the total fleet full LCA results in terms of energy consumption and $\mathrm{CO}_{2}$ emissions (see Fig. 15). If no alternative solutions are adopted, the total life cycle energy consumption increase in 2050 goes up to 58\% when compared to the reference year of 2009 . The most attractive scenario concerning energy consumption is Scenario 3 which, in spite of increasing the total life cycle energy consumption in the 2009-2050 timeframe by $5 \%$, reduces the total life cycle energy consumption by $34 \%$ in 2050 compared to the baseline scenario (Sc. 1). For $\mathrm{CO}_{2}$ emissions, if no alternative solutions are adopted, the total life cycle $\mathrm{CO}_{2}$ emissions increases in 2050 by $31 \%$ comparing to 2009 , but can be reduced in 2050 by $18 \%$ or $39 \%$ compared to the Scenario 1 if Scenarios 2 and 3 are applied.

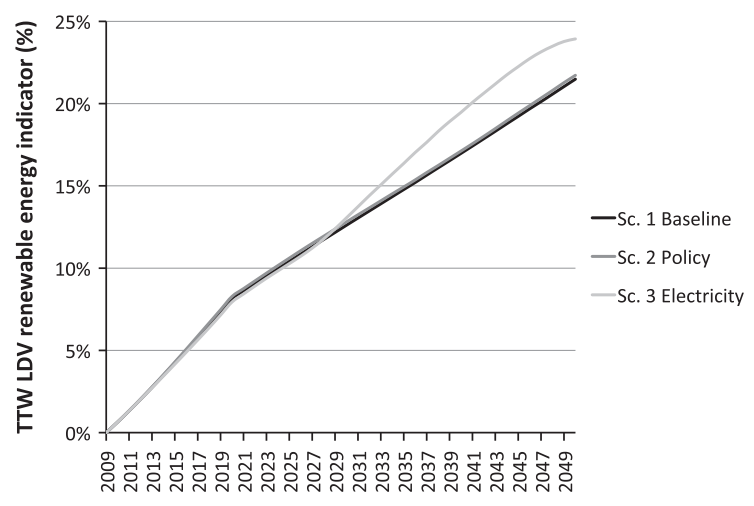

Fig. 16. Scenarios 1, 2 and 3 TTW renewable energy indicator in the 2009-2050 period for the Flores' LDV fleet.

A TTW renewable indicator was also estimated, in order to understand which part of the total TTW energy consumption comes from renewable sources (either from biofuels or renewable electricity) (see Fig. 16). By introducing biofuels and electricity powered vehicles in the fleet of Flores, up to $22-24 \%$ of TTW energy consumption can be shifted from fossil fuels to Renewable Energy 
Sources in 2050. This growth is due to increasing penetration of electricity powered vehicles, but mainly since to the increase incorporation of biofuels.

\section{Conclusions}

The results presented in the network impact section, given the assumptions made, lead to the conclusion that the island's electricity network is ready for EV arrival, at least until 2020. Thereafter, depending on the EV and PHEV sales evolution, some problems may start appearing such as low voltage profiles and very high peak loads, due to the high simultaneity between the conventional grid consumption and the EV additional energy demand. Low voltage issues are easily resolved as it only requires the adjustment of the swing bus voltage to 1.05 p.u.. To control the peak load increase and avoid the need for additional generation power, a smart charging scheme should be implemented in order to manage EV energy demand according to the network technical limitations.

The envisaged smart charging scheme proved to be an efficient method to reduce the peak load, thus contributing to decrease the energy losses in the island. Furthermore, it improved the voltage profiles and reduced the overall grid congestion in the peak hours.

Regarding the electricity mix results obtained for 2020 and 2050 scenarios, it is possible to conclude that the presence of RES should be reinforced in order to accompany the EV increasing energy demand. This is the only way to reduce the island's dependency on fossil fuels and, consequently, the $\mathrm{CO}_{2}$ emitted to the atmosphere. Nevertheless, as the most suitable types of RES to be installed in the island are variable (hydro power) and intermittent (wind power), additional system services should be required from EV in order to maintain a safe operation of the system. Namely, primary frequency control should be provided by EV to avoid high frequency variations in the network [41].

Summarizing, two scenarios were analyzed having as a reference scenario 1 . Scenario 1 considers no EV penetration, while Scenarios 2 and 3 correspond to a shift in 2050 to electricity powered vehicles of $30 \%$ and $70 \%$ respectively. Scenario 3 , with a high penetration of electricity powered vehicles, is disadvantageous regarding energy losses in the grid. The increase in energy consumption due to EVs has much higher impact over losses than the charging approaches implemented. Nevertheless, the losses reduction attained with the smart charging, when compared with the dumb charging, should not be neglected. In terms of the full life cycle assessment, if no alternative solutions are adopted, the total life cycle energy consumption and $\mathrm{CO}_{2}$ emissions will increase in 2050 by $58 \%$ and $31 \%$ respectively in comparison with the 2009 situation. However, if alternative solution such as Scenarios 2 and 3 are envisaged, that evolution can be reversed. The most attractive scenario is Scenario 3 with energy and $\mathrm{CO}_{2}$ emissions reductions in 2050 compared to Scenario 1 of $34 \%$ and $39 \%$ correspondingly.

These results confirm that electricity powered vehicles can be suitable as alternative vehicle technologies for small islands such as the island of Flores, Portugal. Additionally, regarding the wellknown benefits of electricity powered vehicles, such as noise reduction and no local pollutants emissions, it is proven in this paper that these electricity powered vehicle technologies can be handled by the Flores island's existing electricity distribution infrastructure and reveal gains in the total full life cycle assessment associated to the road transportation sector.

\section{Acknowledgments}

This work is financed by the ERDF - European Regional Development Fund through the COMPETE Programme (operational programme for competitiveness) and by National Funds through the
FCT - Fundação para a Ciência e a Tecnologia (Portuguese Foundation for Science and Technology) within projects «MicroGrids + EV - FCOMP-01-0124-FEDER-009866», "SMAGIS - PTDC/SEN-ENR/ 113094/2009», «DYMONDS - CMU-PT/SIA/0043/2009» and «Power demand estimation and power system impacts resulting of fleet penetration of electric/plug-in vehicles - MIT-Pt/SES-GI/0008/ 2008». Thanks are also due to Fundação para a Ciência e Tecnologia (FCT) for the Post-doctoral financial support (SFRH/BPD/79684/ 2011) and to Sillicon Valley Community Foundation through Cisco University Research Program Fund under Gift Number 201190060 .

\section{References}

[1] EUROSTAT. Environment and energy, EUROPA Eurostat - data navigation tree; 2013. <http://ec.europa.eu/eurostat> [cited May 2013].

[2] DGEG - General directorate for energy and geology, energy balance database; 2012. <http://www.dgeg.pt/>.

[3] EEA. Towards a resource-efficient transport system TERM 2009: indicators tracking transport and environment in the European Union; 2010.

[4] Madurell $\mathrm{T}$ et al. European Parliament motion for a resolution - rules of procedure on electric vehicles; 2010.

[5] MEI. Vision paper for the EU Strategic Energy Technology Plan by Ministry of Economy and Innovation; 2007.

[6] MEI. Electric mobility, Portugal - a pioneer in defining a national model by Ministry of Economy and Innovation, Lisbon; 2009.

[7] Baptista P, Tomás M, Silva C. Plug-in hybrid fuel cell vehicles market penetration scenarios. Int J Hydrogen Energy 2010;35(18):10024-30.

[8] Portuguese Government. Press release on "Incentives and objectives of electric vehicle masiification"; 2009.

[9] DGEG. Statistics - fuel sales. General directorate for energy and geology; 2013. <http://www.dgeg.pt/>.

[10] EU, RED Directive - Directive 2009/28/EC of the European Parliament and of the Council of 23 April 2009 on the promotion of the use of energy from renewable sources and amending and subsequently repealing directives 2001/ 77/EC and 2003/30/EC; 2009.

[11] Amoroso Francesco, Cappuccino Gregorio. Advantages of efficiency-aware smart charging strategies for PEVs. Energy Convers Manage 2012;54:1-6.

[12] Bandivadekar A et al. Reducing the fuel and greenhouse gas emissions of the US vehicle fleet. Energy Policy 2008;36(7):2754-60.

[13] Wang Can, Cai Wenjia, Lu Xuedu, Chen Jining. $\mathrm{CO}_{2}$ mitigation scenarios in China's road transport sector. Energy Convers Manage 2007;48:2110-8.

[14] Peças Lopes JA, Soares FJ, Almeida PM, Baptista PC, Silva CM, Farias TL. Quantification of technical impacts and environmental benefits of electric vehicles integration on electricity grids. In: 8th International symposium on advanced electromechanical motion systems, Lille, France; 2009.

[15] Regional statistics service of the Azores; $2010 .<$ <ttp:/ estatistica.azores.gov.pt/>.

[16] Insurance Institute of Portugal. Statistics - insured vehicle fleet in Portugal; $2009<$ <http://www.isp.pt/NR/exeres/7D383D46-9431-416E-98C7395B0A9E7080.htm>.

[17] Zachariadis T, Samaras Z, Zierock K. Dynamic modeling of vehicle populations: an engineering approach for emissions calculations. Technol Forecast Soc Chang 1995:50:135-49.

[18] TIS Consulting. Assessment study of the relation transportation/energy in Azores - 2015. Project ERAMAC-2; 2005.

[19] National Institute of Statistics. Survey on the mobility of the population. National Institute of Statistics, Editor; 2000.

[20] Electricity of Azores. Characterization of transmission and distribution of electricity of the Azores; 2009. <http://www.eda.pt/index.php>.

[21] Electricity of Azores. Statistical information; 2011. <http://www.eda.pt/ index.php>.

[22] Baptista P, Silva C, Farias T. Energy and $\mathrm{CO}_{2}$ emissions scenarios of introducing new vehicle technologies in the Portuguese fleet. In: International advanced mobility forum 2010, Geneve, Switzerland; 2010.

[23] Baptista P, Silva C, Farias T, Heywood J. Energy and environmental impacts of alternative pathways for the Portuguese road transportation sector. J Energy Policy 2012;51:802-15.

[24] Moura F. Car organ transplant - anticipating energy and environmental benefits of cleaner technologies. Departamento de Engenharia Civil. Universidade Técnica de Lisboa. Lisbon: Instituto Superior Técnico; 2009.

[25] ACAP. Statistics - vehicle sales. Automobile Association of Portugal; 2010.

[26] Bandivadekar A. Evaluating the impact of advanced vehicle and fuel technologies in U.S. light-duty vehicle fleet. In: Engineering systems division. Massachusetts Institute of Technology, Boston; 2008.

[27] Silva C, Farias T. Life cycle analysis of fuel cell hybrid plug-in vehicles. In: 17th World hydrogen energy conference, Brisbane, Australia; 2008.

[28] Katrašnik Tomaž. Energy conversion phenomena in plug-in hybrid-electric vehicles. Energy Convers Manage 2011;52:2637-50.

[29] Silva C, Ross M, Farias T. Evaluation of energy consumption, emissions and cost of plug-in hybrid vehicles. Energy Convers Manage 2009;50(7):1635-43. 
[30] Demirbas Ayhan. Biofuels sources, biofuel policy, biofuel economy and globa biofuel projections. Energy Convers Manage 2008;49:2106-16.

[31] Concawe. EUCAR, CONCAWE and JRC joint evaluation of the well-to-wheels energy use and greenhouse gas (GHG) emissions for a wide range of potential future fuels and powertrains options; 2007.

[32] Wipke K, Cuddy M, Burch S. ADVISOR 2.1: a user friendly advanced powertrain simulation using a combined backward/forward approach. IEEE Trans Veh Technol 1999;48:1751-61.

[33] Burnham A, Wang M, Wu Y. Development and applications of Greet 2.7 - the transportation vehicle-cycle model. Energy Systems Division, Argonne National Laboratory, work supported by the U.S. Department of Energy's FreedomCAR and Vehicle Technologies Program (Office of Energy Efficiency and Renewable Energy); 2006.

[34] Zachariadis T. On the baseline evolution of automobile fuel economy in Europe, technological forecasting and social change. Energy Policy 2006;34:1773-85.

[35] Baker H, Cornwell R, Koehler E, Patterson J. Review of low carbon technologies for heavy goods vehicles, Ricardo; 2009
[36] IEA. Energy technology perspectives, scenarios and strategies to 2050 by International Energy Agency; 2010.

[37] Peças Lopes JA, Soares FJ, Almeida PMR. Integration of electric vehicles in the electric power system. Proc IEEE 2011;99(1):p-183.

[38] Guille C, Gross G. A conceptual framework for the vehicle-to-grid (V2G) implementation. Energy Policy 2010;37(11):4379-90.

[39] Peças Lopes JA, Rocha Almeida PM, Soares FJ, Moreira CL. Electric vehicles in isolated power systems: conceptual framework and contributions to improve the grid resilience. In: CMTEE 2010. Conference on control methodologies and technology for energy efficiency, Vilamoura: Portugal; 2010.

[40] INE. Consumption of electricity $(\mathrm{kW} \mathrm{h})$ by geographic localization and Type of consumption, National Institute of Statistics; 2010.

[41] Peças Lopes JA, Rocha Almeida PM, Soares FJ. Using vehicle-to-grid to maximize the integration of intermittent renewable energy resources in islanded electric grids. In: ICCEP 2009. International conference on clean electrical power renewable energy resources impact, Italy, Capri; 2009. 